WORLD VIEW

\title{
The epidemiology of ocular trauma in rural Nepal
}

\section{S K Khatry, A E Lewis, O D Schein, M D Thapa, E K Pradhan, J Katz}

Br J Ophthalmol 2004;88:456-460. doi: 10.1136/bjo.2003.030700

Series editors: W V Good and S Ruit See end of article for
authors' affiliations ....................

Correspondence to: J Katz, ScD, Johns Hopkins Bloomberg School of Public Health, $615 \mathrm{~N}$ Wolfe Street, Room W5009, Baltimore, MD 21205-2103; jkatz@ jhsph.edu

Accepted for publication 28 October 2003
Aims: To estimate the incidence of ocular injury in rural Nepal and identify details about these injuries that predict poor visual outcome.

Methods: Reports of ocular trauma were collected from 1995 through 2000 from patients presenting to the only eye care clinic in Sarlahi district, Nepal. Patients were given a standard free eye examination and interviewed about the context of their injury. Follow up examination was performed 2-4 months after the initial injury.

Results: 525 cases of incident ocular injury were reported, with a mean age of 28 years. Using census data, the incidence was 0.65 per 1000 males per year, and 0.38 per 1000 females per year. The most common types of injury were lacerating and blunt, with the majority occurring at home or in the fields. Upon presentation to the clinic, $26.4 \%$ of patients had a best corrected visual acuity worse than 20/60 in the injured eye, while $9.6 \%$ had visual acuity worse than $20 / 400$. $82 \%$ were examined at follow up: $11.2 \%$ of patients had visual acuity worse than $20 / 60$ and $4.6 \%$ had vision worse than $20 / 400$. A poor visual outcome was associated with increased age, care sought at a site other than the eye clinic, and severe injury. $3 \%$ of patients were referred for further care at an eye hospital at the initial visit; $7 \%$ had sought additional care in the interim between visits, with this subset representing a more severe spectrum of injuries.

Conclusions: The detrimental effects of delayed care or care outside of the specialty eye clinic may reflect geographic or economic barriers to care. For optimal visual outcomes, patients who are injured in a rural setting should recognise the injury and seek early care at a specialty eye care facility. Findings from our study suggest that trained non-ophthalmologists may be able to clinically manage many eye injuries encountered in a rural setting in the "developing" world, reducing the demand for acute services of ophthalmologists in remote locations of this highly agricultural country.
O cular trauma is a major cause of monocular blindness and visual impairment throughout the world, although little is known about its epidemiology or associated visual outcome in developing countries. ${ }^{12}$ A review suggested that at least half a million people are monocularly blind from ocular trauma worldwide. ${ }^{3}$

A national population based survey of blindness in Nepal (1981) found a blindness prevalence rate of $0.84 \%$, with trauma responsible for $7.9 \%$ of monocular blindness. ${ }^{4-6}$ In Nepal, "corneal trauma and ulceration" is the second most common cause of monocular blindness after cataract. ${ }^{6}$ Superficial corneal trauma sustained specifically in agricultural societies such as Nepal often leads to rapidly progressing corneal ulceration and visual loss. ${ }^{36}$ An ideal data collection system for ocular injury includes: (1) population based comparisons using a known denominator; (2) a record of demographic data and details of injury at time of clinical presentation; (3) physician's diagnosis and visual acuity at presentation; and (4) the final outcome for this injury with appropriate follow up care. ${ }^{4}$ We were able to apply much of this model to our data.

This study aimed to estimate incidence of ocular trauma in a rural area of Nepal, identify the risk factors for trauma, describe the visual acuity in the injured eye at time of clinical presentation, and assess visual outcomes 2-4 months after the injury occurred.

\section{METHODS}

This study collected prospective case series data from all patients presenting with ocular trauma between November 1995 through May 2000 to the primary eye care centre run by Nepal Nutrition Intervention Project-Sarlahi (NNIPS) under the auspices of the Nepal National Society for Comprehensive
Eye Care and Sushil Kedia Seva Mandhir. This clinic was originally established in 1991 as part of a large USAID sponsored vitamin A supplementation trial (NNIPS) conducted collaboratively by Johns Hopkins University Bloomberg School of Public Health and the Nepal National Society for Comprehensive Eye Care. Over the past decade, the group has been responsible for a number of population based nutrition, health, and blindness prevention research projects in the east central terai (plains) district of Sarlahi, along the Indian border, revealing public health interventions that reliably lower maternal and child mortality, morbidity, and nutritional blindness. Incidence of trauma was calculated for those individuals who lived within the 30 village development communities (VDCs) of the NNIPS study area, using recent census data from those 30 VDCs. The primary eye care centre provided the only free allopathic eye care offered in the district at the time of the study. Owing to the longstanding relationship that exists between this community and the NNIPS Project, as well as the 4-6 hour distance by bus to other specialty eye care, it is likely that the clinic evaluated almost all severe cases of ocular trauma in the 30 VDCs.

Trauma was defined by patient or parental report of recent eye injury for which care was sought. Patient interviews and eye examinations were conducted by a single senior ophthalmic assistant with 15 years of experience in this district. Information collected included the type, cause, and location of injury, whether alternative forms of treatment had been sought, time between injury and presentation, and demographic data.

The eye examination consisted of visual acuity using a (tumbling E) Early Treatment of Diabetic Retinopathy Study (ETDRS) chart, anterior segment examination by slit lamp 
including fluorescein stain, intraocular pressure measured with a Shiotz tonometer, and, if possible, given the condition of the eye, a posterior segment examination after pupil dilatation.

Clinical features of the injury were recorded and categorised as "severe" or "mild." Severe injuries were corneal ulcer, cataract, penetrating foreign body, corneal rupture, iridodialysis, iris prolapse, dislocated lens, scleral rupture, corneal blood stain, macular/retinal damage and hyphaema. Mild injuries were lid laceration, superficial foreign body, conjunctival tear, subconjunctival haemorrhage, and traumatic uveitis. If a patient complained of a recent injury but the ophthalmic assistant did not note a particular diagnosis, these "injuries" were categorised as mild. For injuries with multiple diagnoses, those with any "severe" component were categorised as severe, and those without a severe component were considered "mild." Trauma cases in need of treatment beyond the scope of the clinic were referred to eye hospitals in neighbouring districts, or to an eye hospital in Kathmandu.

The patients' corrected visual acuities were categorised as having corrected vision worse than 20/400 (WHO definition of blindness) or vision worse than 20/60 (WHO definition of visual impairment) in the injured eye. Because information on bilateral eye injuries did not appear to differ by eye, the right eye was selected for analysis.

Two to four months following the injury, the ophthalmic assistant attempted to visit the homes of all enrolled patients to measure visual outcomes in the injured eye.

Patients who were at least 16 years of age, or who were younger than 16 but were married and no longer living with parents, provided verbal informed consent to participate. If a patient was younger than 16 years old, consent was obtained from at least one parent. Ethical approval for this study was given by the Committee on Human Research of the Johns Hopkins Bloomberg School of Public Health, and by the Nepal Health Research Council.

\section{Statistical methods}

In order to predict visual acuity at 2-4 month follow up, two regression models were fitted, one predicting follow up visual acuity worse than $20 / 60$ as the outcome in the affected eye, and the other with acuity worse than 20/400. An initial model for visual acuity was made based on the bivariate associations significant at the 0.05 level. Predictors included in the regression models were demographics (age, sex, literacy), care seeking behaviour (time and location of first treatment), and "severe" versus "mild" injury. Stepwise logistic regression methods were used to determine a "parsimonious" model.

\section{RESULTS}

Of the 751 patients who presented with ocular trauma over the 4 year study, $650(86.6 \%)$ were from Sarlahi district. A total of $525(69.4 \%)$ patients from the NNIPS area, who presented with their first eye injury during the study period, comprised the cases for this analysis.

\section{Population based incidence of ocular trauma}

Using the number of new cases presenting at the clinic over 4 years, along with census data collected door to door by NNIPS staff in 2001, annual incidence was calculated by age and sex (table 1). The crude incidence of ocular trauma was 0.51 per 1000 population at risk per year (95\% CI 0.47 to $0.56)$. Incidence peaked at 40-49 years for both sexes; 0.65 per 1000 males per year (95\% CI 0.58 to 0.72 ), and 0.38 per 1000 females per year ( $95 \%$ CI 0.32 to 0.42 ). The relative risk of injury for males compared to females was 1.74 (95\% CI 1.45 to 2.09 ).
Of the 525 patients, $342(65.1 \%)$ were male and 183 $(34.9 \%)$ were female. Age ranged from newborn to 87 years, with a mean of 28.1 years, although the distribution of age differed between males and females (see table 1).

The most common occupations were farming, domestic work, and student. Literacy was reported among $51 \%$ of men, and $31 \%$ of women (table 2). Of the 525 incident cases, 239 $(45.5 \%)$ were right eyes, $280(53.3 \%)$ were left eyes, and six $(1.1 \%)$ were bilateral injuries. The most common types of injuries were lacerations $(73.3 \%)$, and the places where injuries most commonly occurred were at home $(32 \%)$, or in the field $(27 \%)$. The first place that care was sought was more likely to be at the primary eye care clinic $(48.5 \%)$ than at the local pharmacy, "doctor," or health post $(42 \%)$, or at home with a shaman or local medicine person (10\%). For individuals whose injury was categorised as "severe," the distributions of demographic and injury characteristics were similar to that of the larger population (table 2).

If treatment was first sought outside of this clinic, at locations such as a local pharmacy, health post, or medicine shop (as it was for $51.5 \%$ of patients), the mean time to seeking treatment was 2.5 days. The mean time between occurrence of injury and seeking eye care at this eye clinic was 7.8 days. The mean time between the injury and any form of eye care, regardless of location, was 7 days.

\section{Diagnosis at presentation}

In all, 355 of the 525 cases (68\%) were categorised as "severe" injuries; over $75 \%$ of these severe cases had lacerating injuries, with $6 \%$ blind and 13\% visually impaired at the 2-4 month follow up (table 2).

Topical treatment was offered to $99.4 \%$, and systemic treatment to $12.8 \%$ of patients. Surgery was performed on about $19 \%$ of patients at initial presentation. Only $15(2.9 \%)$ of the 525 were referred by the ophthalmic assistant for more advanced treatment, and more than $50 \%$ of those were referred to Birganj Eye Hospital, the shortest distance for most individuals to travel. Of the injuries referred, more than half were blunt injuries that occurred at home.

Visual acuity could not be measured in 56 patients at clinical presentation. Of these, $73 \%$ were age 5 or younger, and visual acuity measurement was not attempted. Of the $469(89.3 \%)$ patients with measurable visual acuity, 45 $(9.6 \%)$ had corrected visual acuity $<20 / 400$ in the injured eye at initial presentation for care, while $124(26.4 \%)$ had corrected visual acuity $<20 / 60$ (tables 2 and 3).

\section{Visual acuity at 2-4 month examination}

Of the 525 cases of ocular trauma, 431 (82.1\%) were seen at follow up; 82 were known to be alive but had permanently moved, and two had died. Of the 94 individuals who were not seen again, $73 \%$ had initially been categorised as $20 / 20$ or better. There was no statistically significant difference in visual acuity between those lost and those seen at follow up $(\mathrm{p}=0.97$ for $\mathrm{VA}<20 / 60, \mathrm{p}=0.48$ for $\mathrm{VA}<20 / 400)$. Of the $43 \mathrm{l}$ who were followed, $392(91.0 \%)$ had a measurable visual acuity; $4.6 \%$ of individuals had a corrected visual acuity of $<20 / 400$ in the injured eye, and $11.2 \%$ had visual acuity $<20 / 60$ in that eye. The majority of patients demonstrated an improved visual acuity, and this was seen across all age groups. At the time of follow up, 29 people $(6.7 \%)$ had sought additional treatment for their injury. These injuries were most commonly of the lacerating type, occurred in the fields, and were caused by a plant or stick. Sixty four per cent of those 29 had gone to the Nepal Eye Hospital in Kathmandu, a bus ride of 8-12 hours. Of these 29, 22 were self referred and seven had been referred by the ophthalmic assistant. Characteristics for these subgroups are compared in table 4 . The percentage of injuries categorised as "severe" did 
Table 1 Annual ocular trauma incidence by sex and age $(n=525)$, between November 1995 and May 2000

\begin{tabular}{|c|c|c|c|c|c|c|c|c|}
\hline \multirow[b]{2}{*}{$\begin{array}{l}\text { Age group } \\
\text { (years) }\end{array}$} & \multicolumn{4}{|l|}{ Males } & \multicolumn{4}{|l|}{ Females } \\
\hline & $\begin{array}{l}\text { Population* } \\
\text { (No) }\end{array}$ & $\begin{array}{l}\text { New cases } \\
\text { (No) }\end{array}$ & $\begin{array}{l}\text { Distribution of } \\
\text { new cases (\%) }\end{array}$ & $\begin{array}{l}\text { Incidence (per } \\
1000 \text { per year) }\end{array}$ & $\begin{array}{l}\text { Population* } \\
\text { (No) }\end{array}$ & $\begin{array}{l}\text { New cases } \\
\text { (No) }\end{array}$ & $\begin{array}{l}\text { Distribution of } \\
\text { new cases (\%) }\end{array}$ & $\begin{array}{l}\text { Incidence (per } \\
1000 \text { per year) }\end{array}$ \\
\hline$<15$ & 51483 & 64 & 18.7 & 0.31 & 48411 & 52 & 28.4 & 0.27 \\
\hline $15-19$ & 14919 & 30 & 8.8 & 0.50 & 13450 & 20 & 10.9 & 0.37 \\
\hline $20-29$ & 24705 & 92 & 26.9 & 0.93 & 24062 & 38 & 20.8 & 0.40 \\
\hline $30-39$ & 18176 & 61 & 17.8 & 0.84 & 16259 & 30 & 16.4 & 0.46 \\
\hline $40-49$ & 10871 & 50 & 14.6 & 1.15 & 8767 & 26 & 14.2 & 0.74 \\
\hline $50+$ & 11232 & 45 & 13.2 & 1.00 & 11332 & 17 & 9.3 & 0.38 \\
\hline Total & 131386 & 342 & & $\begin{array}{l}0.65(95 \% \mathrm{Cl}: 0.58 \\
\text { to } 0.72)\end{array}$ & 122281 & 183 & & $\begin{array}{l}0.38(95 \% \mathrm{Cl}: 0.32 \\
\text { to } 0.52)\end{array}$ \\
\hline
\end{tabular}

*These numbers are based on door to door census taken by NNIPS staff March-May 2001.

not differ significantly $(\mathrm{p}=0.50)$ between groups, or when compared with the $68 \%$ of larger group $(p=0.13)$. The visual acuities for these subgroups (both initially and at the 24 month examination) appear to be worse than those who did not receive additional clinical care for their injury. Severity of injury and clinical diagnoses differed by subgroup.

\section{Statistical modelling of visual acuity}

For follow up acuity $<20 / 60$ or $<20 / 400$ in the injured eye, risk factors included in the parsimonious regression model were age, sex, literacy, paramedical treatment versus eye

Table 2 Distribution of characteristics of cases $(n=525)$

\begin{tabular}{|c|c|c|}
\hline & No (\%) & $\begin{array}{l}\text { Among severe* } \\
\text { injuries }(\%)\end{array}$ \\
\hline \multicolumn{3}{|l|}{ Occupation } \\
\hline Farmer & $136(25.9)$ & $97(27.3)$ \\
\hline Domestic work & $113(21.5)$ & $85(23.9)$ \\
\hline Student & $85(16.2)$ & $47(13.2)$ \\
\hline Day/unskilled labour & $55(10.5)$ & $40(11.3)$ \\
\hline $\begin{array}{l}\text { Private service (skilled, } \\
\text { salaried, factory) }\end{array}$ & $31(5.9)$ & $19(5.4)$ \\
\hline Business (shopkeeper, vendor) & $30(5.7)$ & $19(5.4)$ \\
\hline \multicolumn{3}{|l|}{ Literate (yes) } \\
\hline Males & $174(50.9)$ & $120(51.3)$ \\
\hline Females & $57(31.2)$ & $37(30.6)$ \\
\hline \multicolumn{3}{|l|}{ Type of injury } \\
\hline Lacerating & $385(73.3)$ & $310(87.3)$ \\
\hline Blunt & $98(18.7)$ & $20(5.6)$ \\
\hline $\begin{array}{l}\text { Small penetrating }(<1 / 3 \\
\text { corneal diameter) }\end{array}$ & $18(3.4)$ & $12(3.4)$ \\
\hline $\begin{array}{l}\text { Large penetrating ( }>1 / 3 \\
\text { corneal diameter) }\end{array}$ & $8(1.5)$ & $8(2.2)$ \\
\hline Chemical burn & $7(1.3)$ & $3(0.8)$ \\
\hline \multicolumn{3}{|l|}{ Location of injury occurrence } \\
\hline Home & $168(32.0)$ & $102(28.7)$ \\
\hline Fields/agriculture & $144(27.4)$ & $93(26.2)$ \\
\hline Road & $72(13.7)$ & $44(12.4)$ \\
\hline Factory & $44(8.4)$ & $39(11.0)$ \\
\hline Construction site & $14(2.7)$ & $12(3.4)$ \\
\hline \multicolumn{3}{|l|}{ Place of treatment first sought } \\
\hline Self/family/neighbour/shaman & $52(9.9)$ & $35(9.9)$ \\
\hline Paramedical† & $218(41.6)$ & $145(41.0)$ \\
\hline NNIPS primary eye care centre & $254(48.5)$ & $174(49.2)$ \\
\hline VA distribution, initial & $(n=469)$ & $(n=328)$ \\
\hline Normal & $300(64.0)$ & $184(56.1)$ \\
\hline$V A<20 / 60$ & $124(26.4)$ & $101(30.8)$ \\
\hline $\mathrm{VA}<20 / 400$ & $45(9.6)$ & $43(13.1)$ \\
\hline VA distribution, follow up & $(n=392)$ & $(n=272)$ \\
\hline Normal & $330(84.2)$ & $219(80.5)$ \\
\hline$V A<20 / 60$ & $44(11.2)$ & $36(13.2)$ \\
\hline$V A<20 / 400$ & $18(4.6)$ & $17(6.2)$ \\
\hline \multicolumn{3}{|c|}{$\begin{array}{l}\text { *Severe injury ( } \mathrm{n}=355 \text { ) was defined as deep (>1/3 corneal thickness) } \\
\text { foreign body, corneal ulcer, corneal rupture, corneal blood stain, } \\
\text { cataract, dislocated lens, iridodialysis, iris prolapse, scleral rupture, } \\
\text { hyphaema, macula/retinal damage. } \\
\dagger^{\prime \prime} \text { Paramedical" includes care sought at local pharmacy, local medicine } \\
\text { shops or clinics with medical or paramedical workers, health posts, and } \\
\text { non-eye care hospital. }\end{array}$} \\
\hline
\end{tabular}

clinic treatment, and injury categorised as severe versus mild (table 5). While the odds of blindness in the injured eye increased with age (OR 1.03, 95\% CI 1.00 to 1.06 ), severe injury appeared to contribute the greatest risk, with an odds ratio of 8.04 (95\% CI 1.02 to 63.42), followed by treatment at a paramedical facility (OR $4.15,95 \%$ CI 1.42 to 12.10 ). Literacy offered a significant protective effect in all models. Similar risk factors predicted visual acuity worse than 20/60 (table 5).

Likelihood ratio tests indicated that the parsimonious models both for blindness and for visual impairment were similar at predicting visual acuity when compared to the more comprehensive models ( $\mathrm{p}=0.92$ for blindness, $\mathrm{p}=0.60$ for visually impaired).

\section{DISCUSSION}

The primary eye care centre in Sarlahi serves the entire district of approximately 607823 people (Khatry S, personal communication, 25 April 2003), although cases came from outside the district, and even from India. The population of the 30 NNIPS VDCs was 253667 in 2001, or a third of the district. The 525 trauma cases that lived within the 30 differed in literacy when compared to that reported in past studies of the same population. A previous NNIPS study reported that $13-16 \%$ of the female population was literate, ${ }^{7}$ while we found much higher rates $(31 \%)$. This suggests that the population seeking care for ocular trauma was more literate (suggestive of a higher socioeconomic status) than those in the general population of the NNIPS study area. The differences may be that cases of ocular trauma differ from the general population, or because groups differ in care seeking behaviour (Katz J, personal communication, 28 April 2003)..$^{78}$

The apparent association between poor visual acuity and increasing age may be due to several phenomena. Age alone may be a risk factor for a new eye injury, but it may also be responsible for worsening vision unrelated to ocular injury (that is, cataract). Socioeconomic factors may also have a role, as access to care may change with age. A visit to a clinic or hospital also requires taking time from work, and a more socioeconomically stable individual is more capable of this. The eye care provided at this clinic was free for all individuals. We cannot say, based on these data, that the differences in incidence by varied risk factors is related to the injuries themselves, or to a difference in access to care.

The lag between injury occurrence and care seeking was associated with a worse visual outcome in our models, and may reflect not only the type of injury, but also economic constraints beyond a lack of awareness about treatment options. Those individuals with more severe injuries (that is, lacerating or penetrating) may seek care earlier, although there may be little that can be done to save sight. ${ }^{5}$ Those with less severe injuries who do not seek care may suffer 
Table 3 Clinical presentation and associated visual acuity

\begin{tabular}{|c|c|c|c|c|c|}
\hline Clinical presentation & $\begin{array}{l}\text { Distribution: } \\
\text { Number (\%) }\end{array}$ & $\begin{array}{l}\text { VA }<20 / 60 \text { at } \\
\text { presentation }(\%)(n=469)\end{array}$ & $\begin{array}{l}\text { VA }<20 / 400 \text { at } \\
\text { presentation ( } \%)\end{array}$ & $\begin{array}{l}\text { VA }<20 / 60 \text { at follow } \\
\text { up }(\%)(n=392)\end{array}$ & $\begin{array}{l}\text { VA }<20 / 400 \text { at follow } \\
\text { up }(\%)\end{array}$ \\
\hline Corneal ulcer† & $264(50.3)$ & $32.1^{* *}$ & $13.3^{* *}$ & 12.5 & 5.8 \\
\hline Foreign body $\dagger$ & $177(33.7)$ & $5.6^{* * *}$ & $1.9^{* \star *}$ & $0.8^{* * *}$ & $0^{* * *}$ \\
\hline $\begin{array}{l}\text { Subconjunctival } \\
\text { haemorrhage }\end{array}$ & 70 (13.3) & $10.2^{* *}$ & 3.4 & 3.9 & 0 \\
\hline Traumatic uveitis & $68(13.0)$ & $75.8^{* * *}$ & $41.9^{* * *}$ & $45.3^{\star * *}$ & $26.4^{* * *}$ \\
\hline "Other" iris damage $†$ & $47(9.0)$ & $78.8^{* * *}$ & $38.1^{* \star *}$ & $27.8^{* * *}$ & $22.2^{* * *}$ \\
\hline Cataract† & $28(5.3)$ & $78.6^{* \star *}$ & $35.7^{* * *}$ & $63.2^{\star \star *}$ & $26.3^{* * *}$ \\
\hline Conjunctival tear & $12(2.3)$ & 10 & 10 & 0 & 0 \\
\hline Corneal rupture $†$ & $7(1.3)$ & $80.0^{* *}$ & $40.0^{* * *}$ & $40.0^{* *}$ & $20.0^{* *}$ \\
\hline Iridodialysis† & $7(1.3)$ & $100^{* * *}$ & $66.7^{* * *}$ & $66.7^{* *}$ & $50.0^{* * *}$ \\
\hline Dislocated lens $†$ & $7(1.3)$ & $85.7^{* \star *}$ & $57.1^{* * *}$ & $57.1^{\star \star *}$ & $57.1^{* * *}$ \\
\hline Scleral rupture $†$ & $6(1.1)$ & $100^{* * *}$ & 25 & 33.3 & 33.3 \\
\hline Iris prolapse† & $6(1.1)$ & $100^{* * *}$ & $66.7^{* * *}$ & 40.0 & $40.0^{*}$ \\
\hline Hyphaemat & $4(0.8)$ & $100^{* *}$ & $50^{*}$ & 0 & 0 \\
\hline Corneal blood staining & $2(0.4)$ & 100 & 50 & $100^{*}$ & 0 \\
\hline Macula/retinal damage $†$ & $2(0.4)$ & 0 & 0 & 0 & 0 \\
\hline
\end{tabular}

secondary infections and lose vision through progressive corneal scarring. ${ }^{5}$ This lack of care seeking is not restricted to rural environments, however. In a study of lifetime prevalence of ocular trauma in Baltimore, Katz and Tielsch found that care was not sought for $18 \%$ of ocular injuries ( $22 \%$ for black and $14 \%$ for white people), even though $15 \%$ of white and $8 \%$ of black people monocularly blind as a result of trauma said they had not sought treatment for the injury. ${ }^{9}$ Educating patients about the proper place and timing of treatment is fundamental to an improved visual outcome.

The most common locations for injury were similar to findings from the Nepal Blindness Survey where $70 \%$ of trauma cases involved either agriculture or domestic work. ${ }^{5}$ Agriculture accounts for about one half of the country's gross national product, and is thought to employ more than nine tenths of the workforce..$^{10}$ One study estimated the incidence of eye injuries in agriculture to be 3.5 per 10000 , compared with construction (5.3 per 10000 ), and industry (1.9 per 10 000). ${ }^{11}$ This suggests the need for better monitoring of rural occupational injuries.

The low rate of referral of patients for further treatment indicated to us that this experienced ophthalmic assistant was comfortable diagnosing and treating most of the eye injuries that presented in the clinic. Those referred and treated had more severe injuries and poorer visual outcomes, suggesting the more difficult cases were those referred. Injury types and locations differed among those who were referred (blunt, in the home) and those who sought additional care without a referral (lacerating, in the field). We can speculate that more people sought additional treatment than expected because those particular individuals felt that the ophthalmic assistant at the Hariaun clinic could not properly treat their injuries. These individuals also appeared to have more severe injuries than the case series, but less severe injuries than those referred by the ophthalmic assistant. They may have

Table 4 Characteristics of individuals receiving additional eye care after initial assessment by ophthalmic assistant (OA)

\begin{tabular}{|c|c|c|c|}
\hline & $\begin{array}{l}15 \text { initially referred } \\
\text { for more advanced } \\
\text { care }\end{array}$ & $\begin{array}{l}22 \text { not initially referred } \\
\text { by OA, but self referred } \\
\text { in interim }\end{array}$ & $\begin{array}{l}\text { Comparison to larger } \\
\text { group of } 525 \text { ocular } \\
\text { trauma patients }\end{array}$ \\
\hline Age (years) (SD)* & $25.7(24.0)$ & $41.2(13.1)$ & $28.1(16.4)$ \\
\hline$\%$ "severe" injuries $\dagger$ & $14(93.3 \%)$ & $16(76.2 \%)$ & $355(68 \%)$ \\
\hline Median number of days to & $10(35.7)$ & $4(6.3)$ & $4(7.8)$ \\
\hline \multirow{2}{*}{\multicolumn{4}{|c|}{ Initial VA }} \\
\hline & & & \\
\hline$V A<20 / 60 \ddagger$ & $11(91.7 \%)$ & $13(61.9 \%)$ & $124(26.4 \%)$ \\
\hline $\mathrm{VA}<20 / 400 \ddagger$ & $9(75 \%)$ & $7(33.3 \%)$ & $45(9.6 \%)$ \\
\hline \multicolumn{4}{|l|}{ VA at 2-4 month follow up } \\
\hline$V A<20 / 60 \ddagger$ & $10(76.9 \%)$ & $10(47.6 \%)$ & 44 (11.2\%) \\
\hline$V A<20 / 400 \ddagger$ & $7(53.8 \%)$ & $6(28.6 \%)$ & $18(4.6 \%)$ \\
\hline \multicolumn{4}{|l|}{ Most common injuries } \\
\hline & Any iris damage $§(11)$ & Corneal ulcer (13) & Corneal ulcer (264) \\
\hline & Traumatic uveitis (10) & Tramuatic uveitis (9) & Foreign body (177) \\
\hline & Corneal ulcer (5) & Any iris damage $\neq$ (8) & $\begin{array}{l}\text { Subconjunctival } \\
\text { Hemorrhage (70) }\end{array}$ \\
\hline & Cataract (4) & Lid damage (8) & Traumatic uveitis (68) \\
\hline & Dislocated lens (3) & Hypopyon (4) & Iris damage $\ddagger(60)$ \\
\hline & Corneal rupture (2) & Cataract (4) & Cataract (28) \\
\hline & Retinal damage (2) & Corneal rupture (2) & Conjunctival tear (12) \\
\hline
\end{tabular}

*Group of 15 and group of 22 were found to differ significantly at 0.05 level.

† Group of 15 differed significantly from larger group of 525 at 0.05 level.

$\ddagger$ Both the group of 15 and the group of 22 had a significantly worse visual acuity the group of 525 at the 0.001 level, but did not significantly differ from each other.

§lnjuries included iris prolapse, iridodialysis, or other iris damage. 
Table 5 Logistic regression models for prediction of visual acuity (VA) at follow up

\begin{tabular}{|c|c|c|c|c|}
\hline \multirow[b]{2}{*}{ Variable } & \multicolumn{2}{|l|}{ Comprehensive model } & \multicolumn{2}{|l|}{ Parsimonious model* } \\
\hline & $\begin{array}{l}\text { OR }(95 \% \mathrm{Cl}) \text { for } \\
\mathrm{VA}<20 / 60\end{array}$ & $\begin{array}{l}\text { OR }(95 \% \mathrm{Cl}) \text { for } \\
\text { VA }<20 / 400\end{array}$ & $\begin{array}{l}\text { OR }(95 \% \mathrm{Cl}) \text { for } \\
\text { VA }<20 / 60\end{array}$ & $\begin{array}{l}\text { OR }(95 \% \mathrm{Cl}) \text { for } \\
\text { VA }<20 / 400\end{array}$ \\
\hline \multicolumn{5}{|l|}{ Demographics } \\
\hline Age (years) & 1.04 (1.02 to 1.07$)$ & $1.03(1.00$ to 1.06$)$ & 1.05 (1.02 to 1.07$)$ & $1.03(1.00$ to 1.06$)$ \\
\hline Sex & $1.05(0.50$ to 2.19$)$ & $0.54(0.18$ to 1.64$)$ & $1.10(0.54$ to 2.22$)$ & $0.59(0.19$ to 1.65$)$ \\
\hline Literacy & $0.20(0.08$ to 0.49$)$ & $0.05(0.01$ to 0.41$)$ & $0.20(0.08$ to 0.48$)$ & $0.05(0.01$ to 0.42$)$ \\
\hline \multicolumn{5}{|c|}{ Place of treatment first sought: (compared to Hariaun clinic) } \\
\hline Self/neighbour/shaman & $0.90(0.25$ to 3.26$)$ & $0.57(0.06$ to 6.60$)$ & & \\
\hline Paramedical & $2.47(1.17$ to 5.20$)$ & 3.75 (1.19 to 11.8$)$ & 2.39 (1.21 to 4.73$)$ & $4.15(1.42$ to 12.10$)$ \\
\hline \multicolumn{5}{|c|}{ Time to treatment first sought: (compared to day 1) } \\
\hline lst week & $1.11(0.47$ to 2.61$)$ & $1.28(0.36$ to 4.53$)$ & & \\
\hline More than 1 week & $1.34(0.38$ to 4.67$)$ & $1.14(0.17$ to 7.72$)$ & & \\
\hline \multicolumn{5}{|c|}{ Clinical presentation (severe compared to mild) } \\
\hline Severe injury† & $1.89(0.81$ to 4.43$)$ & 8.26 (1.04 to 65.43$)$ & & 8.04 (1.02 to 63.42$)$ \\
\hline \multicolumn{5}{|c|}{$\begin{array}{l}\text { "Determined using forward, backward, and stepwise regression methods with inclusion criteria of } \mathrm{p}<0.05 \text {, fixing age and sex into the model. } \\
\text { †Severe injury ( } \mathrm{n}=355 \text { ) was defined as deep ( }>1 / 3 \text { corneal thickness) foreign body, corneal ulcer, corneal rupture, corneal blood stain, cataract, dislocated lens, } \\
\text { iridodialysis, iris prolapse, "other" iris damage, scleral rupture, hyphaema, macula/retinal damage. } \\
\text { Values in bold if confidence intervals do not contain } 1.0 \text {. } \\
\text { "Paramedical" includes care sought at local pharmacy, local medicine shops or clinics with medical or paramedical workers, health posts, and non-eye care } \\
\text { hospitals. }\end{array}$} \\
\hline
\end{tabular}

been better off economically and therefore more able to travel far distances and leave work to seek care. This study has a role in estimating a rural population's needs for acute services of ophthalmologists, as it appears to support the notion that a trained non-ophthalmologist can provide most of what is needed. It also demonstrates the potential impact of education about injury prevention and treatment.

One strength of this study was the use of a locally undertaken door to door census to estimate incidence of ocular trauma in a defined area, which has not been done in many studies in developing countries. The incidence in men was greater than in women, similar to what has been reported previously. ${ }^{1411} 12$ It is possible that the lower incidence among women may be due to their poorer access to care. However, this difference between men and women is seen in many populations including the United States, so it is likely that at least some part of this finding is due to the difference in exposure risk between men and women.

Another strength was that $82 \%$ of cases were seen $2-$ 4 months after initial presentation to the clinic, allowing a comparison of initial with final visual acuity. Since most patients will never have access to corneal transplants or corneal repair, the vision at this time is likely to be their ultimate visual acuity. In addition, a single clinician examined patients using a slit lamp, eliminating intraobserver error, and ETDRS charts were used to determine acuity.

The census data used to calculate incidence were from 2001, a year after the study ended. Any increase in population size during that time would likely lead to an underestimate of the incidence. The incidence may also be underestimated if patients had gone elsewhere for treatment, if they did not seek treatment for minor injuries, or if access to or utilisation of care was problematic.

Ocular trauma in developing countries has not been studied extensively. This study indicates that it is a significant cause of monocular vision loss in all age groups, and an experienced non-ophthalmologist can treat a large proportion of these successfully. Many injuries and their resulting vision loss may be prevented through education about prompt and appropriate care seeking.

\section{ACKNOWLEDGEMENTS}

This study was carried out under Cooperative Agreement HRNA-00-97-00015-00 between Office of Nutrition, US Agency for International Development (USAID), Washington, DC, and the Center for Human Nutrition (CHN), Department of International Health, and the Sight and Life Research Institute, Johns Hopkins University, Bloomberg School of Public Health, Baltimore, MD, USA. It was a joint undertaking between the CHN and the Nepal National Society for Comprehensive Eye Health Care, Kathmandu, Nepal.

\section{Authors' affiliations}

S K Khatry, M D Thapa, J Katz, Nepal Nutrition Intervention ProjectSarlahi (NNIPS), Nepal Netra Jyoti Sangh, PO Box 335, Tripureswor, Kathmandu, Nepal

A E Lewis, E K Pradhan, J Katz, Department of International Health, Johns Hopkins Bloomberg School of Public Health, 615 North Wolfe Street, Baltimore, MD 21205, USA

O D Schein, J Katz, Dana Center for Preventive Ophthalmology, Wilmer Eye Institute, Johns Hopkins School of Medicine Health, 600 North Wolfe Street, Baltimore, MD 21205, USA

\section{REFERENCES}

1 Koval MD, Teller J, Belkin M, et al. The Israeli Ocular Injuries Study. Arch Ophthalmol 1988;106:776-81.

2 Jackson H. Bilateral blindness due to trauma in Cambodia. Eye 1996; 10:517-20.

3 Thylefors B. Epidemiological patterns of ocular trauma. Aust N Z J Ophthalmol 1992;20:95-8.

4 Schein OD, Hibberd PL, Shingleton BJ, et al. The spectrum and burden of ocular injury. Ophthalmology 1988;95:300-5.

5 Seva Foundation. Epidemiology of blindness in Nepal. Ch 9, Trauma. Chelsea, MI: Seva Foundation, 1988.

6 Upadhyay MP, Karmacharya PCD, Koirala S, et al. Epidemiologic characteristics, predisposing factors, and etiologic diagnosis of corneal ulceration in Nepal. Am J Ophthalmol 1991;111:92-9.

7 West KP, Katz J, Khatry SK, et al. Double blind, cluster randomized trial of low dose supplementation with vitamin $\mathrm{A}$ or beta-carotene on mortality related to pregnancy in Nepal. BMJ 1999;318:570-5.

8 Christian P, West KP, Khatry SK, et al. Vitamin A and beta-carotene supplementation reduces but does not eliminate maternal night blindness in Nepal. J Nutr 1998;128:1458-63.

9 Katz J, Tielsch JM. Lifetime prevalence of ocular injuries from the Baltimore Eye Survey. Arch Ophthalmol 1993;111:1564-8.

10 NepalNet: an electronic networking for sustainable development in Nepal. www.panasia.org.sg/nepalnet/facts_fig2.htm, accessed 22 April 2003.

11 Saari KM, Aine E. Eye injuries in agriculture. Acta Ophthalmol Suppl 1984;161:42-51

12 McCarty CA, Fu CLH, Taylor H, et al. Epidemiology of ocular trauma in Australia. Ophthalmology 1999;106:1847-52. 